Bull. Mater. Sci., Vol. 18, No. 5, September 1995, pp. 531 539. Printed in India.

\title{
Preparation and characterization of ultra-thin cobalt silicide for VLSI applications
}

\author{
S KAL, I KASKO ${ }^{\dagger}$ and $\mathrm{H}$ RYSSEL ${ }^{\dagger}$ \\ Microelectronics Centre, Department of Electronics and Electrical Communication Engineering. \\ Indian Institute of Technology, Kharagpur 721302 . India \\ ${ }^{+}$Lehrstuhl fur Elektronische Bauelemente. Universitat Erlangen-Nurnberg, Cauerstrasse 6. \\ D-91058, Erlangen. Germany
}

MS received 29 April 1995

\begin{abstract}
Ultra-thin cobalt silicide $\left(\mathrm{CoSi}_{2}\right)$ was formed from $10 \mathrm{~nm}$ cobalt film by solid phase reaction of $\mathrm{Co}$ and $\mathrm{Si}$ by use of rapid thermal annealing (RTA). The $\mathrm{Ge}^{+}$ion implantation through Co film caused the interface mixing of the cobalt film with the silicon substrate and resulted in a homogeneous silicide layer. XRD was used to identify the silicide phases that were present in the film. The metallurgical analysis was performed by RBS. XRD and RBS investigations showed that final RTA temperature should not exed $800 \mathrm{C}$ for thin $(<50 \mathrm{~nm}) \mathrm{CoSi}_{2}$ formation.
\end{abstract}

Keywords. $\operatorname{CoSi}_{2}:$ RTA: XRD; RBS.

\section{Introduction}

Metal silicides are extensively used in very large scale integrated circuit device processing as interconnects, Schottky barriers, ohmic contacts and low resistivity gates (Murarka 1983). Both decrease in device dimensions and a drive for very high speed have increased the demand for improved interconnects with low resistance/capacitance ( $R C$ ) coupling. Thin films of refractory metal silicides have been the subject of much interest in recent years owing to their widespread use as contact materials in VLSI. The ability of etching procedures for selectively removing unreacted metal over the oxide without etching the silicide film formed on silicon surfaces allows for the self alignment placement of contacts. Thus a self aligned silicide (SALICIDE) process has been proposed in VLSI and VHSIC circuit technologies to reduce the RC time constant contributed by the source, drain and gate areas (Murarka 1983; Revegz et al 1983). For VLSI use, the silicides must possess a wide combination of properties among which the most important is its resistivity. Among the refractory metal silicides, $\mathrm{TiSi}_{2}$ and $\mathrm{CoSi}_{2}$ with resistivities in the range of 15-20 $\mu \mathrm{ohm} \mathrm{cm}$ are the best conductors (Nicolet and Lau 1983; Park et al 1984).

Although titanium silicide ( $\mathrm{TiSi}_{2}$ ) has been drawing more attention in recent years as an integrated circuit metallization, cobalt silicide with its excellent properties is used in modern VLSI processes. The formation of $\mathrm{TiSi}_{2}$ by thermal silicidation is very sensitive to the oxygen or other impurities (carbon or nitrogen) present in the annealing gas ambient (Taur et al 1987). The restriction on the annealing gas ambient is less critical for Co than for $\mathrm{Ti}$. $\mathrm{CoSi}_{2}$ has many other desirable properties. Cobalt is unreactive to titanium. Therefore, the use of Co should make the deposition of clean films easier and should reduce the risk of reaction with oxide films. Thus the SALICIDE process using the $\mathrm{CoSi}_{2}$ is more simple.

The final thickness of the $\mathrm{TiSi}_{2}$ layer will depend on the deposited $\mathrm{Ti}$ film thickness, the reaction temperature and the reaction time. This is contrary to the Co-silicidation reaction, where the resulting silicide thickness is exactly defined by the deposited Co film 
thickness. $\mathrm{CoSi}_{2}$ produces fairly low stress when film is formed on $\mathrm{Si}$ and it shows good resistances to most plasma processes (Tabasaki et al 1987). Because of these advantages, $\mathrm{CoSi}_{2}$ seems to be an attractive alternative to $\mathrm{TiSi}_{2}$.

As device geometries are scaled down to smaller dimensions, conventional furnace annealing for silicide formation are now being replaced by rapid thermal annealing (RTA). This method avoids oxidation problem originated in furnace annealing. It is also shown that RTA yields smooth high conductivity $\mathrm{CoSi}_{2}$ films free of problems associated with furnace annealing (Yachi 1984; Tabasaky et al 1987).

The ion-beam mixing can break up the native oxide at the metal/Si interface and achieve interface mixing that enhances metal-Si reaction rate and results in smooth silicide/silicon interface. Ion-beam mixing with low doses does not produce detectable silicide layers but it is known that above a critical dose the properties of the silicide formed by subsequent annealing are drastically improved. Only mixing at doses greater than equal to a critical dose results in an abrupt silicide-silicon interface, in a smooth surface morphology and in low specific resistivity values (Hamdi and Nicolet 1984; Ku et al 1990; Kasko et al 1992).

In most of the recent sub-micron VLSI, shallow junctions (100-200 nm) are present under the cobalt region. The encroachment of the contact silicide into the depletion region of the junction can cause excessive leakage currents. Now a days devices are made on thin $(\sim 100 \mathrm{~nm})$ silicon film of a silicon-on-insulator (SOI) substrate. In such devices, contact silicide thickness must be very thin in order to have proper device characteristics. Successful contacts in such thin films can be formed by using thinner than typical (100-200 nm thick) silicides. Thus the formation of ultra-thin silicide film draws a special attention in VLSI process.

The formation of ultra-thin $(<50 \mathrm{~nm})$ silicides requires an optimal control of silicidation process and potential to scale down the process. Thinner $\mathrm{CoSi}_{2}$ films showed severe agglomeration and consequently, an increase in room temperature sheet resistance upon moderate annealing (Phillips et al 1990). One cost effective method of ultra-thin silicide formation, compatible with the self-aligned technology, would be low energy ion-beam mixing of Ge into thin (10-12 nm) cobalt film followed by two-step moderate RTA. Formation and evaluation of ultra-thin ion-beam mixed $\mathrm{CoSi}_{2}$ films $(<50 \mathrm{~nm})$ produced by sputter deposition of $\mathrm{Co}$ on $\mathrm{Si}$ has been discussed in this paper. The structural and electrical properties of the $\mathrm{CoSi}_{2}$ films are presented in $\S 3$.

\section{Preparation of ultra-thin $\mathrm{CoSi}_{2}$ films}

Thin films of $10-12 \mathrm{~nm}$ Co were deposited by sputtering on $\mathrm{N}$-type $\langle 100\rangle \mathrm{Si}$ substrate. All the wafers were chemically cleaned and dipped in $1 \% \mathrm{HF}$ to remove the native oxide layer immediately before loading in the sputtering chamber. The vacuum before sputtering was better than $2 \times 10^{-6}$ torr, the pressure during sputtering with argon was $7 \times 10^{-4}$ torr. The thickness of the cobalt films were measured from the step heights of the surface profile obtained from Solan DEKTAK II. The thickness of the cobalt film varied from 9.9 to $12 \mathrm{~nm}$. Thermal silicidation of cobalt conventionally involves the conversion of the complete Co film to the CoSi phase through an intermediate $\mathrm{Co}_{2} \mathrm{Si}$ phase during a first thermal treatment and a second conversion to the final silicide phase, $\mathrm{CoSi}_{2}$, during a subsequent thermal treatment. 


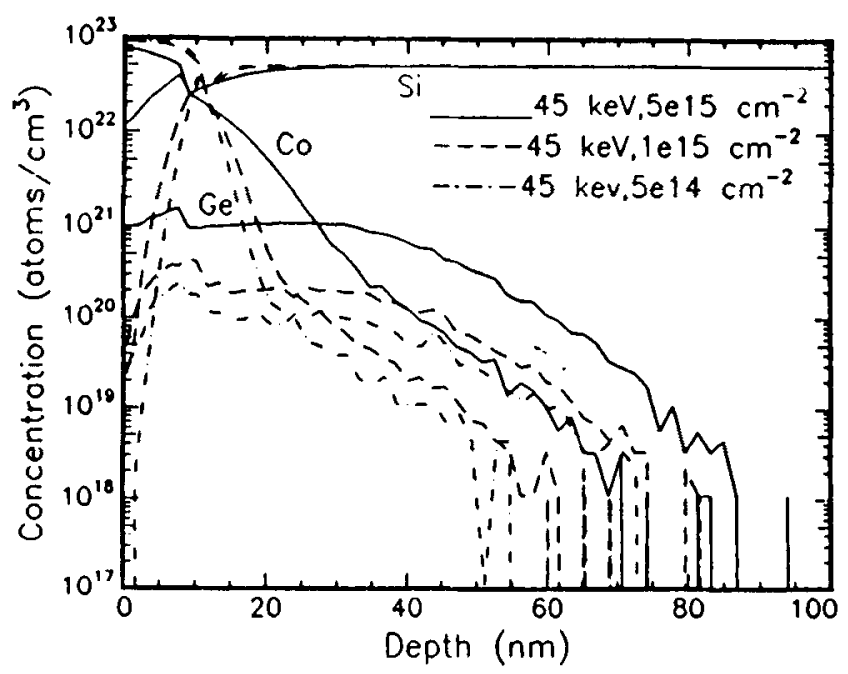

Figure 1. Dynamic Monte Carlo (T-DYN) simulated concentration profiles of Ge, Co and Si after ion-beam mixing of Ge.

After Co sputtering, the as-deposited samples were implanted with Ge ions at an energy of $45 \mathrm{keV}$. The energy was chosen from the simulation results with the dynamic MonteCarlo program TRIM (T-DYN) (Biersack et al 1991). The simulation was done for germanium implantation in $10 \mathrm{~nm}$ cobalt film deposited on single crystal Si substrate. Concentration profiles of $\mathrm{Ge}, \mathrm{Co}$ and $\mathrm{Si}$ are calculated from T-DYN data and the results are shown in figure 1. The $\mathrm{Ge}$ concentration necessary for $\mathrm{Si}$ amorphization is $\sim 2.7 \times 10^{19}$ atoms/cc (Kasko et al 1992). The thickness of the amorphous silicon layer after implantation of $\mathrm{Ge}$ at dose $1.0 \times 10^{15} \mathrm{~cm}^{-2}$ is about $48 \mathrm{~nm}$. During the $\mathrm{CoSi}_{2}$ silicidation process, silicon will be consumed and the thickness of the $\mathrm{CoSi}_{2}$ layer obtained from $10-12 \mathrm{~nm}$ Co is $\sim 35-42 \mathrm{~nm}$. Thus the silicidation reaction will take place completely in amorphized Si for the Ge mixing dose of $1.0 \times 10^{15} \mathrm{~cm}^{-2}$. The $\mathrm{Ge}^{+}$ion mixed Co deposited wafers were subsequently annealed in a rapid thermal annealing system (Heat Pulse 610, AG Associates) in Ar ambient at a peak temperature of $700^{\circ} \mathrm{C}$ for 45 sec. The first annealing process leads to the formation of thin $\mathrm{Co}_{2} \mathrm{Si}$ film between the $\mathrm{Si}$ substrate and the unreacted Co layer on the top. The unreacted Co-layer was etched using a selective Co etch solution $\left(5 \mathrm{HCl}: 4 \mathrm{H}_{2} \mathrm{O}_{2}: 20 \mathrm{H}_{2} \mathrm{O}\right)$ at a temperature of $30^{\circ} \mathrm{C}$ for $30-60 \mathrm{sec}$. A second thermal treatment followed using RTA at a higher temperature of $800-1000^{\circ} \mathrm{C}$ for $10 \mathrm{sec}$ to form the final $\mathrm{CoSi}_{2}$ phase. The process sequence for silicide preparation is shown in figure 2 .

\section{Characterization of the $\mathrm{CoSi}_{2}$ film}

To understand the progress of the reaction after the RTA process, the sheet resistance of $\mathrm{CoSi}_{2}$ was measured by Four-Point Probe measurements. X-ray diffraction (XRD) employing $\mathrm{Cu} \mathrm{K}_{x}$ radiation $(\lambda=1.5418 \mathrm{~A})$ was used to identify the silicide phases that were present in the film. The metallurgical analysis was performed by Rutherford back scattering spectroscopy (RBS) with a $2 \cdot 0 \mathrm{MeV}{ }^{4} \mathrm{He}^{+}$ion-beam. 

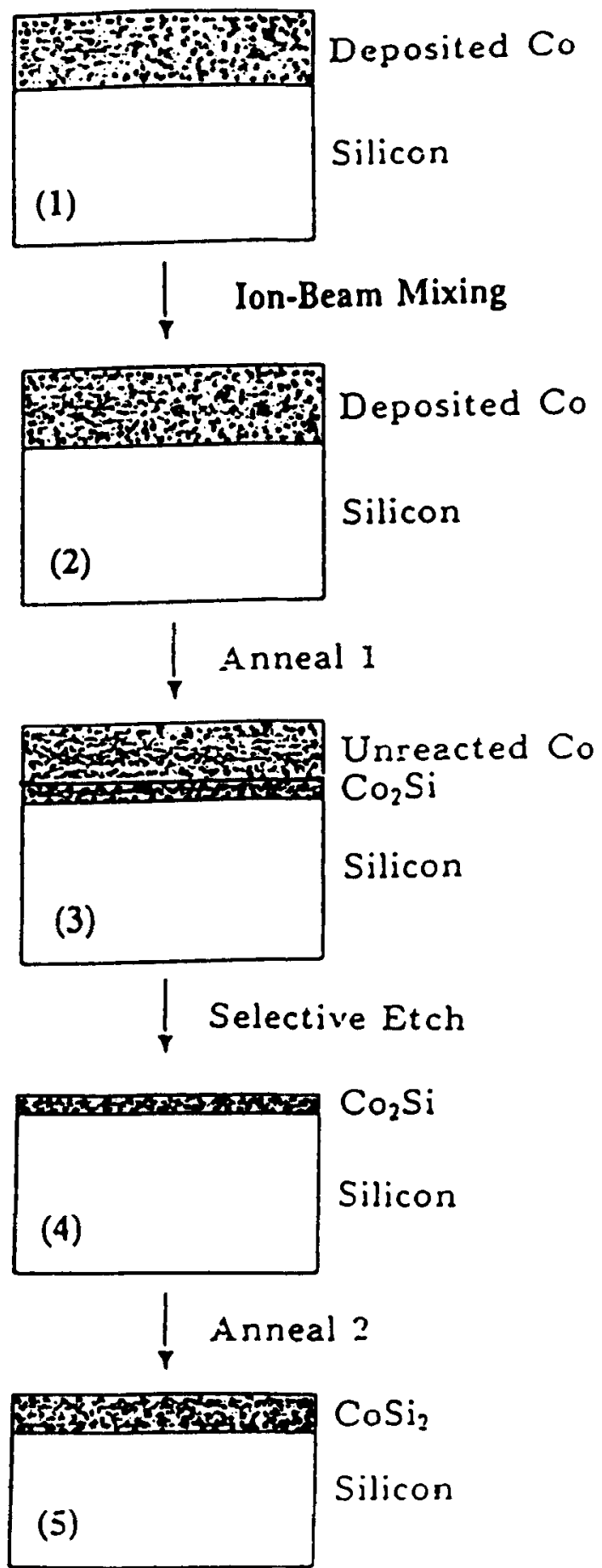

Figure 2. Process sequence of ion-beam mixed cobalt silicide. 


\subsection{Sheet resistance measurements}

Sheet resistance of the $\mathrm{Co}$ film on $\mathrm{Si}$ were measured at different stages of $\mathrm{CoSi}_{2}$ formation using 4-point resistivity method and the results are shown in table 1 . The results indicate that the sheet resistance of the ultra-thin $(\sim 35 \mathrm{~nm}) \mathrm{CoSi}_{2}$ is a little bit higher $(5 \cdot 67 \Omega / \mathrm{sq})$ compared to that of thick cobalt silicide $(3-4 \Omega / \mathrm{sq})$. It was observed from the available literature that sheet resistance increases as the silicide thickness goes down (Maszara 1992). It was also noted that sheet resistance of the samples after second anneal treatment remained almost same as the values obtained after first RTA. It was observed that, if the second anneal was performed at $1000^{\circ} \mathrm{C}$ for $10 \mathrm{sec}$ (as is used in case of thick silicide formation (Kasko et al 1992; Xiao et al 1992)), $\mathrm{CoSi}_{2}$ colour changed to gray and the sheet resistance could not be measured. This change was probably due to the formation of large grains of $\mathrm{CoSi}_{2}$ embedded in $\mathrm{Si}$ which is also confirmed from the XRD analysis in the following section. The results indicated that in case of thin silicide $(<50 \mathrm{~nm})$, the anneal temperature should be within $900^{\circ} \mathrm{C}$ and we had chosen the second RTA parameter as $800^{\circ} \mathrm{C}$ for $10 \mathrm{sec}$.

Sheet resistance mapping of sputter deposited Co film on Si after ion-beam mixing of Ge were measured using Four Dimension Auto Probe Model 280 and is shown in figure 3a. The mean value of sheet resistance was found to be $47.0 \Omega / \mathrm{sq}$ and the corresponding resistivity was obtained as $47 \mu \Omega \mathrm{cm}$ taking the average value of Co thickness as $10 \mathrm{~nm}$. The range of variation of sheet resistance was $1.68 \Omega / \mathrm{sq}$ and the standard deviation was $1 \cdot 106 \%$. Figure $3 \mathrm{~b}$ shows the sheet resistance mapping of the final $\mathrm{CoSi}_{2}$ film after second anneal treatment. $\mathrm{CoSi}_{2}$ was removed at one edge of the wafer to compare the sheet resistance variation from $\mathrm{CoSi}_{2}$ to single crystal $\mathrm{Si}$. The final sheet resistance was much uniform over the entire surface of 4 inch dia wafer. The resistivity of the $\mathrm{CoSi}_{2}$ film after the second RTA was found to be $19.87 \mu \Omega \mathrm{cm}$.

\section{$3.2 X$-ray diffraction $(X R D)$ analysis}

The X-ray diffraction patterns were measured using Philips HR XRD instrument and $d$ values of the intensity peaks were found using Philips diffraction software. The as-deposited $\mathrm{Co}$ film shows intensity peaks of $\mathrm{Co}, \mathrm{Si}, \mathrm{Co}_{2} \mathrm{Si}$ and $\mathrm{CoSi}_{2}$ (figure 4a). Figure $4 \mathrm{~b}$ shows the X-ray diffraction pattern after 2nd RTA of $800^{\circ} \mathrm{C}, 10 \mathrm{sec}$ and only $\mathrm{CoSi}_{2}$ phase is present. Thus silicidation reaction seems to be completed after the second anneal treatment. The results of the XRD pattern of the silicide samples annealed at a temperature of $1000^{\circ} \mathrm{C}, 10 \mathrm{sec}$ (shown in figure $4 \mathrm{c}$ ) indicate that $\mathrm{Si}$ intensity peaks are dominant along with $\mathrm{CoSi}_{2}$ and $\mathrm{CoSi}$ phases. It is presumably due to the formation of large grains of

Table 1. Sheet resistance $(\Omega / \mathrm{sq})$ of $\mathrm{CoSi}_{2}$ films at different stages of silicide formation.

\begin{tabular}{lc}
\hline Process steps & Sheet resistances $(\Omega / \mathrm{sq})$ \\
\hline After Ge & + ion-beam mixing \\
$45 \mathrm{keV}, 1 \times 10^{15} \mathrm{~cm}^{-2}$ & 47 \\
After first RTA: $700^{\circ} \mathrm{C}, 45 \mathrm{sec}$ & 5.82 \\
After second RTA: $800^{\circ} \mathrm{C}, 10 \mathrm{sec}$ & $5 \cdot 67$
\end{tabular}



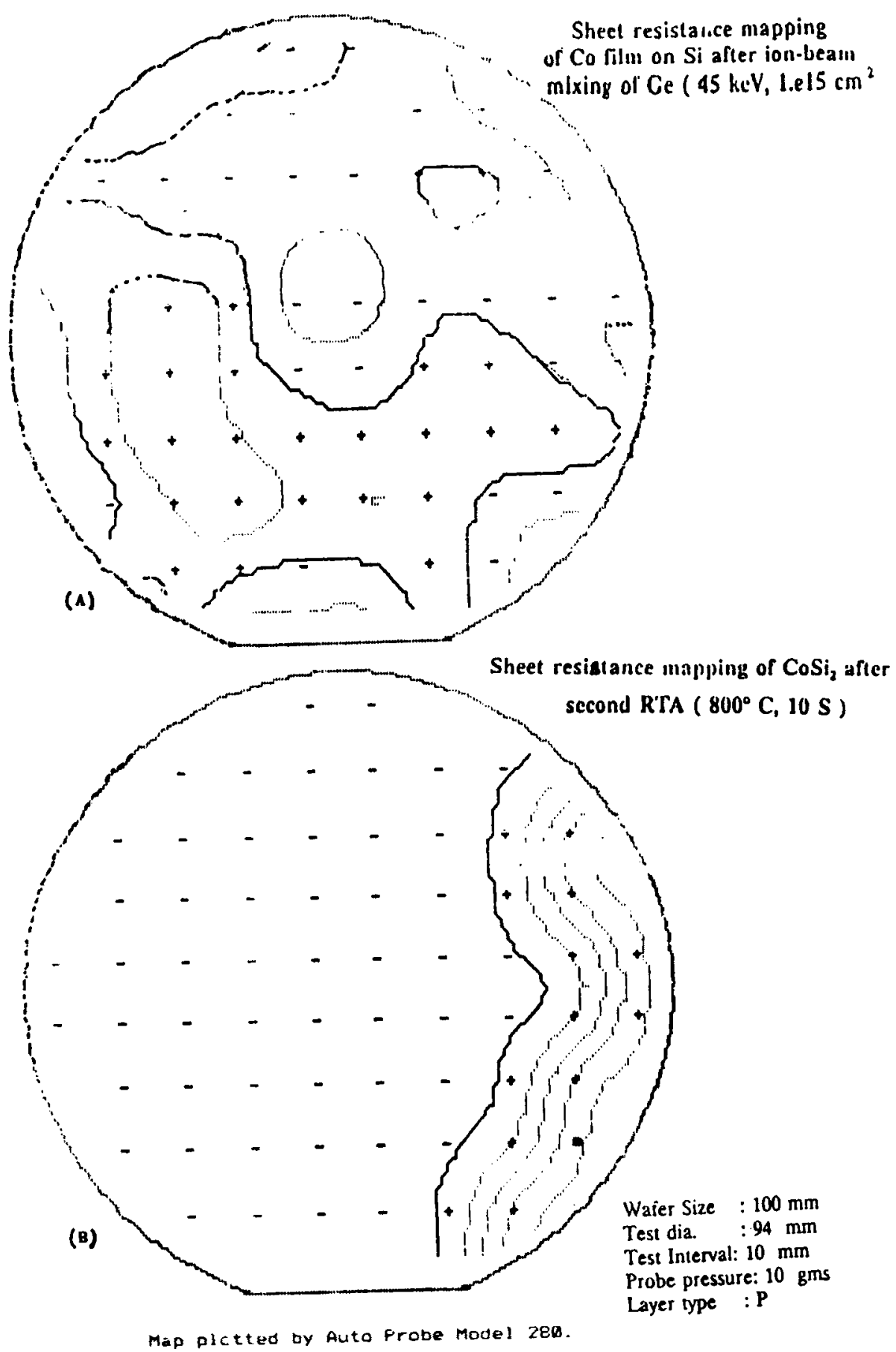

Figure 3. Sheet resistance mapping of (A) sputter deposited Co film on $\mathrm{Si}$ and $(\mathrm{B})$ final $\mathrm{CoSi}_{2}$ layer. 

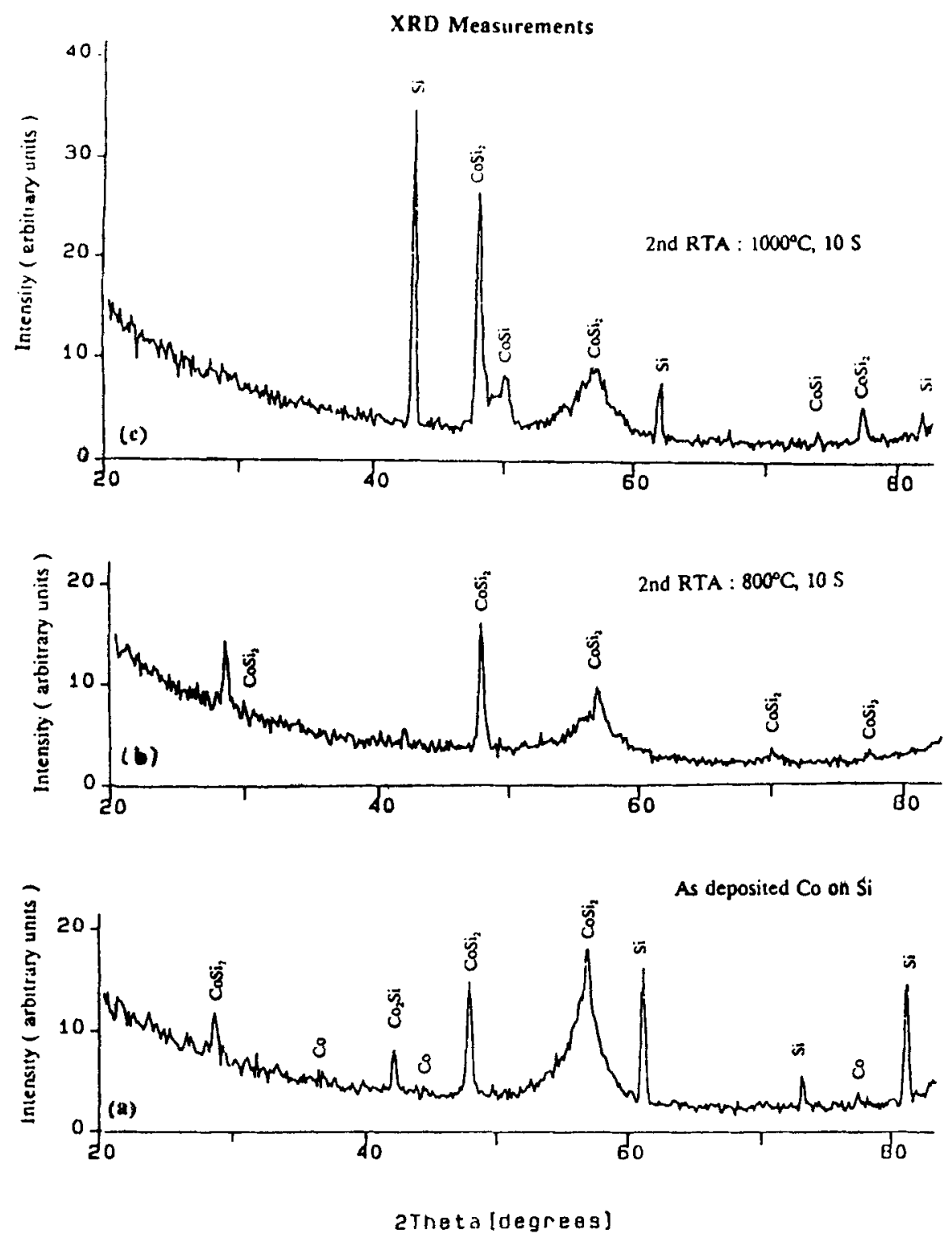

Figure 4. The X-ray diffraction patterns of $\mathrm{CoSi}_{2}$ at various annealing conditions.

$\mathrm{CoSi}_{2}$ and $\mathrm{CoSi}$, which are embedded in silicon. As a result, the colour changes to gray. Sheet resistance at this stage could not be measured.

\subsection{Rutherford back scattering (RBS) analysis}

Rutherford back scattering (RBS) analysis with $2 \mathrm{meV}^{4} \mathrm{He}^{+}$ions was used for detection of silicide reaction. The samples were tilted at an angle of $10^{\circ}$ in respect to the $\mathrm{He}$ beam. 


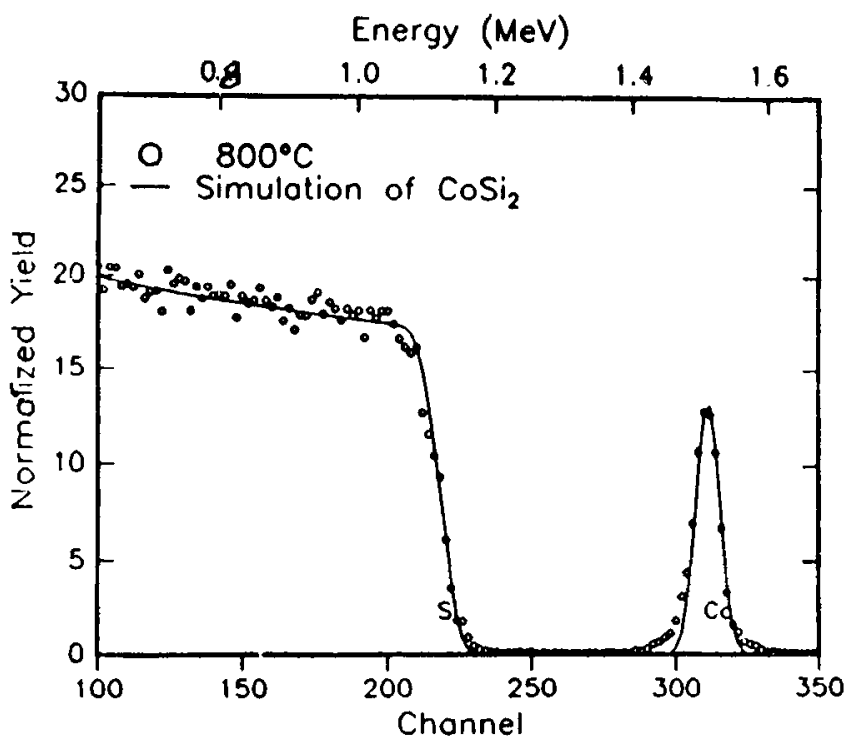

Figure 5. RBS spectra of thin $\mathrm{CoSi}_{2}$ layer.

Typical RBS spectra of $10 \mathrm{~nm}$ Co on Si after ion beam mixing of Ge and two-step RTA at $700^{\circ} \mathrm{C}, 45 \mathrm{sec}$ and $800^{\circ} \mathrm{C}, 10 \mathrm{sec}$ are shown in figure 5. Simulated RBS spectra of $\mathrm{CoSi}_{2}$ (obtained using RUMP software) is also plotted in the same figure for comparison. The results indicate that the experimental and simulated spectra exactly match after second anneal treatment of $800^{\circ} \mathrm{C} 10 \mathrm{sec}$. The equal slope at the left and right sides of the Co peak indicates uniform and homogeneous formation of $\mathrm{CoSi}_{2}$. The thickness of the Co film was calculated from the RBS data and was found to be $11 \mathrm{~nm}$. For RBS measurements, some samples were tilted at an angle of $60^{\circ}$ in respect of He beam for improved depth resolution, but the step at the silicon surface of the yield curve, which was normally found in case of thick $(>50 \mathrm{~nm}$ ) silicide, was not observed because of the thin layer of the cobalt silicide.

\section{Conclusions}

In this work, thin cobalt silicides were prepared from sputtered deposited $10 \mathrm{~nm}$ cobalt film by the solid phase reaction of $\mathrm{Co}$ and $\mathrm{Si}$ using rapid thermal annealing. The cobalt layers were mixed using $45 \mathrm{keV} \mathrm{Ge}{ }^{+}$ions for homogeneous silicidation. A two-step annealing process at $700^{\circ} \mathrm{C}$ for $45 \mathrm{sec}$ and $800^{\circ} \mathrm{C}$ for $10 \mathrm{sec}$ was necessary to achieve $\mathrm{CoSi}_{2}$ formation. The sheet resistance of the thin $(\sim 35 \mathrm{~nm}) \mathrm{CoSi}_{2}$ layer was found to be $5.67 \Omega /$ sq. XRD analysis revealed that $\mathrm{Si}$ and $\mathrm{CoSi}$ phases were present in addition to $\mathrm{CoSi}_{2}$ phase if the final RTA temperature was increased to $1000^{\circ} \mathrm{C}$ for $10 \mathrm{sec}$. The sheet resistance of the samples annealed at $1000^{\circ} \mathrm{C}$, was very high and was difficult to measure. RBS measurements also indicated complete silicidation reaction at an RTA of $800^{\circ} \mathrm{C}$ for $10 \mathrm{sec}$. It is concluded from the investigations under this study that ultra-thin $\mathrm{CoSi}_{2}$ layers needs RTA temperature of $800^{\circ} \mathrm{C}, 10 \mathrm{sec}$ for homogeneous thermal silicidation. 


\section{References}

Biersack J P, Berg S and Neder C 1991 Nucl. Instrum. Meth. B59/60 21

Hamdi A H and Nicolet M A 1984 Thin Solid Films 119357

Kasko I, Dehm C and Ryssel H 1992 Mater. Res. Soc. Symp. Proc. 268289

$\mathrm{Ku}$ Y H, Lee S K and Kwong D L 1990 J. Electrochem. Soc. 137728

Maszara W P 1992 J. Appl. Phys. 711248

Murarka S P 1983 Silicides for VLSI applications (New York: Academic Press)

Nicolet M A and Lau S S 1983 in VLSI electronics (eds) N G Einspruch and G M Larrabe (New York: Academic Press)

Park H K, Sachitano J, Eiden G, Lane E and Yamaguchi T 1984 J. Vac. Sci. Technol. A2 259

Phillups J, Revesz P, Olowolafe J D and Mayer J W 1990 Mater. Res. Soc. Symp. Proc. 18257

Revegz P. Gyimesi J, Poganly L and Peto G 1983 J. Appl. Phys. 542114

Tabasaky M, Bulat E S, Ditchek B M, Sullivan M A and Shatas S C 1987 IEEE Trans. Elec. Dev. ED-34 548

Taur Y, Sun J Y-C, Midy D, Wang L K, Davari B, Klepner S P and Ting C Y 1987 IEEE Trans. Elec. Dev. ED-34 575

Xiao Z G, Rozgonyi G A, Canovi C A and Osburn C M 1992 J. Mater. Res. 7269

Yachi T 1984 IEEE Elec. Dev. Lett. EDL-5 217 